\title{
Intranasal Cold Dry Air Is Superior to Histamine Challenge in Determining the Presence and Degree of Nasal Hyperreactivity in Nonallergic Noninfectious Perennial Rhinitis
}

\author{
JOSEPH P. M. BRAAT, PAUL G. MULDER, WYTSKE J. FOKKENS, ROY GERTH van WIJK, \\ and EVERT RIJNTJES \\ Departments of Ear, Nose and Throat Surgery, Biostatistics, and Allergology, Erasmus University Rotterdam and University Hospital \\ 'Dijkzigt,' Rotterdam; and Department of Ear, Nose and Throat Surgery, Leyenburg Hospital, The Hague, The Netherlands
}

\begin{abstract}
The objective of the study was to compare cold dry air (CDA) and histamine in differentiating patients with nonallergic noninfectious perennial rhinitis (NANIPER) from control subjects. Nasal reactivity (nasal patency, mucus production, and sneezing) in 16 symptomatic nonsmoking patients with NANIPER and seven nonsmoking control subjects was measured with standardized CDA and histamine provocation series in a randomized crossover study. Intranasal CDA resulted in increased mucus production and nasal blockage in a dose-dependent manner in patients with NANIPER but not in control subjects. Sneezing did not occur. The reproducibility of CDA for patency and mucus production was good. Sensitivity for CDA was $87 \%$ compared with $100 \%$ for histamine. However, specificity was $71 \%$ for CDA and $0 \%$ for histamine. It is concluded that the new standardized intranasal CDA provocation method uses a recognizable natural nonspecific stimulus and seems to be more suitable than histamine for characterizing and assessing the presence and degree of nasal reactivity in NANIPER. Braat JPM, Mulder PG, Fokkens WJ, van Wijk RG, Rijntjes E. Intranasal cold dry air is superior to histamine challenge in determining the presence and degree of nasal hyperreactivity in nonallergic noninfectious perennial rhinitis.

AM J RESPIR CRIT CARE MED 1998;157:1748-1755.
\end{abstract}

Nonallergic noninfectious perennial rhinitis (NANIPER) (also referred to as vasomotor rhinitis) was first described by W ihl and colleagues (1). It is a chronic ongoing type of rhinitis characterized by nasal hyperreactivity that results in nasal blockage, mucus production, and sneezing $(2,3)$. The diagnosis is established by exclusion. When patients with noninfectious rhinitis respond negatively to a skin prick test and when symptoms persist throughout the year and no anatomic or medical disorders of the nose are present, the diagnosis points to N A NIPER. No single diagnostic test, symptom, or clinical feature exists to demonstrate the presence of this disorder. Nor have distinct changes been found in cellular patterns in the epithelium and lamina propria of the nasal mucosa (4).

$\mathrm{N}$ asal hyperreactivity is an increased sensitivity of the nasal mucosa to nonspecific stimuli and was first described by van Lier (5). Cold dry air (CD A) provocation has been proven by the Baltimore group to be an effective tool in quantifying the secretory response of hyperreactivity in persons susceptible to $\operatorname{CDA}(6,7)$. In this population, significant changes were found

(Received in original form January 6, 1997 and in revised form December 23, 1997) Supported by Glaxo Wellcome, Ltd, and Artu Biological NV, The Netherlands. Correspondence and requests for reprints should be addressed to J. P. M. Braat, M.D., ENT Drechtsteden Ziekenhuis, Van der Steenhovenplein 1, 3317 NM Dordrecht, The Netherlands.

Am J Respir Crit Care Med Vol 157. pp 1748-1755, 1998

Internet address: www.atsjournals.org in cell mediators and neurogenic reflex mechanisms. It was, however, not clear from which type of rhinitis these subjects suffered or what happened to other nasal parameters such as nasal patency or sneezing, important parameters when studying blockers, runners, and sneezers. Pulmonary CDA provocation of patients with asthma results in bronchial obstruction, and it is found to be a suitable method for assessing bronchial hyperreactivity (8).

$\mathrm{H}$ istamine and methacholine are the most widely used provocation methods for measuring the degree of nasal hyperreactivity today. These tests have not been validated in patients with NA NIPER. The objective of the study was to validate and standardize a new intranasal CD A challenge method and compare it with that of histamine. Nasal patency, mucus production, and sneezing were studied after CDA and histamine challenge in patients with NA NIPER and in control subjects. The dose dependency, sensitivity, specificity, and reproducibility of both challenge methods were compared.

\section{METHODS}

Patients and Control Subjects

Thirty-eight patients and seven control subjects were selected on the basis of inclusion and exclusion criteria (Table 1). These patients had experienced nasal complaints such as nasal obstruction, sneezing, and/ or rhinorrhea for more than $1 \mathrm{yr}$. These symptoms could not be attributed to an atopic rhinitis, nasal or paranasal sinus infection, anatomic disorders affecting nasal function, pregnancy or lactation, and/or systemic disorders. Symptoms 2 wk prior to entry varied from moderate 
TABLE 1

\section{CRITERIA FOR THE SELECTION OF PATIENTS WITH NONALLERGIC NONINFECTIOUS} PERENNIAL RHINITIS (NANIPER) AND CONTROL SUBJECTS

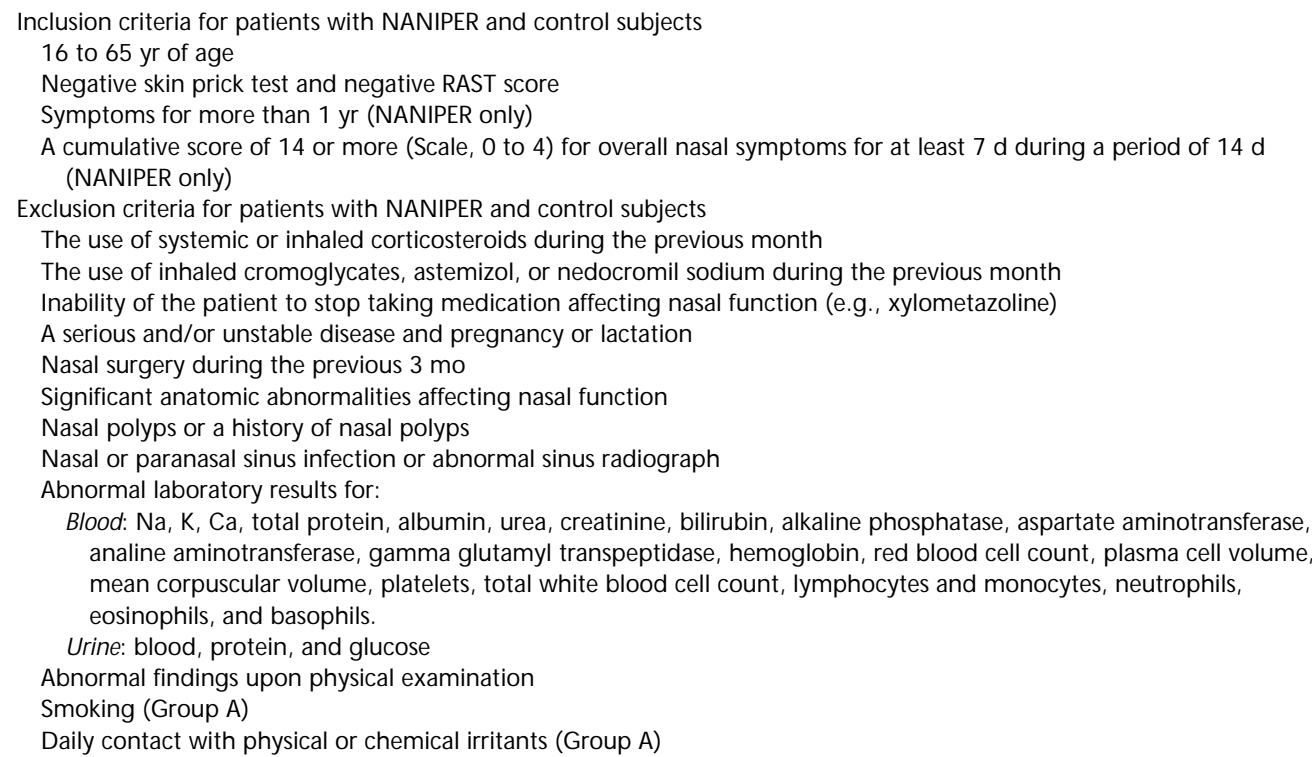

to severe (daily average of 2 , on a scale of 0 to 4 ). L ocal and systemic corticosteroids or antihistamine treatment had been stopped $4 \mathrm{wk}$ prior to the study, and xylometazoline had been stopped $6 \mathrm{hr}$ prior to each visit. There was no history of xylometazoline abuse.

A subgroup of 16 (five male, 11 female) of the 38 patients and all seven control subjects (three male, four female) met additional requirements: they were nonsmokers and avoided physical or chemical irritants during the study (Group A). These additional restrictions were not imposed on a second group of 16 patients ( $G$ roup B), randomly selected from the 22 remaining patients. The study was approved by the local medical ethical committee.

\section{Study Design}

The study had a randomized crossover controlled design. Patient G roup $A$ and the seven control subjects visited the hospital on 16 occasions. Participants were randomly assigned to start either with a CDA challenge period of 4 wk followed by a 4-wk histamine challenge period or vice versa. These periods consisted of three complete provocation series at weekly intervals. Subsequently, five daily repeat challenges followed in order to test for possible increased responsiveness after repeat challenges ( see Table 2).

Patient G roup B visited the hospital twice. A fter the run-in period, patients were subjected to one CDA challenge in order to assess whether patency, mucus production, and/or sneezing data of random NA NIPER sufferers responded to a function derived from the selected patient Group A. The aim of this part of the study was to assess external reproducibility.

\section{Cold Dry Air}

Subjects were allowed to acclimatize to room temperature $\left(20^{\circ} \mathrm{C}\right)$ for $15 \mathrm{~min}$. Patients then blew their noses gently to remove remaining secretions. The nose was then prerinsed with $\mathrm{N}$ saline. A respiratory heat exchanger (J aeger $\mathrm{G} \mathrm{mbH}$, W ürzburg, G ermany) was modified slightly: Before cooling, the air was dried by passing it through a column with silicon granules. The temperature of the air leaving the system was filtered and entered the nose at $-10^{\circ} \mathrm{C}$ with a relative humidity of $<10 \%$. A purpose-designed nose cap (R espricare, The Hague, The Netherlands) ensured a tight fit. The dosage was increased in steps by analogy with the histamine series as follows: 12.5, 25, 50, 100, 200 , and $400 \mathrm{~L}$. This involved CD A provocation steps of $1,1,2,4,8$, and 16 min with a flow of 12.5 for the first step and $25 \mathrm{~L} / \mathrm{min}$ for the following steps. Instructions were given to inhale through the nose and exhale through the mouth during the challenge and to maintain normal breathing frequency as at rest. The provocation was stopped in case of hyperventilation. A nterior rhinomanometry ( $R$ hinoscreen; J aeger) was repeated until no further decrease in patency was measured. Secretions were measured by weighing the amount of mucus produced per provocation step in preweighed paper tissues on a precision scale (M ettler, W ürzburg, G ermany) with an accuracy of $0.01 \mathrm{~g}$. Sneezes were counted. Maximal effects per dose step were used for calculations. R epeat measurements were performed every time the dose was increased. Patency reduction and mucus production were determined and sneezes were counted in the following 5 min (see below). A the $400 \mathrm{~L} C D A$ step, patients were allowed to blow their nose after $8 \mathrm{~min}$ in order to correct for drying of nasal secretions during the 16-min provocation with CDA.

TABLE 2

STUDY DESIGN FOR NANIPER PATIENT GROUP A: TIMETABLE FOR CROSSOVER PROVOCATION SERIES*

\begin{tabular}{|c|c|c|c|c|c|c|c|c|}
\hline \multicolumn{2}{|c|}{ Run-in } & \multicolumn{3}{|c|}{ CDA or Histamine } & \multicolumn{4}{|c|}{ Histamine or CDA } \\
\hline Visits: & 1 & $\underline{2}$ & $\underline{3}$ & $\underline{4} 567 \underline{8}$ & $\underline{9}$ & $\underline{10}$ & $11121314 \underline{15}$ & 16 \\
\hline Days: & 1 & $\frac{14}{x}$ & 21 & 28293031,32 & 39 & $4 \underline{6}$ & $\underline{53} 545556 \underline{57}$ & 64 \\
\hline
\end{tabular}

*Underlines $=$ complete provocation series; boldface $=$ provocation at predefined arbitrary threshold: average of the three previous threshold doses resulting in $0.5 \mathrm{~g}$ mucus production and $30 \%$ patency reduction. 
TABLE 3 OVERVIEW OF CDA THRESHOLD DEFINITIONS

CDA dose
The dose resulting in $40 \%$ reduction of nasal patency and/or $0.5 \mathrm{~g}$ mucus
production (cutoff lines) in one CDA / histamine provocation series
400 dose
The dose $\leqslant 400 \mathrm{~L} \mathrm{CDA} \mathrm{or} \leqslant 4 \mathrm{mg} / \mathrm{ml}$ histamine resulting in $40 \%$ reduction
of nasal patency and/or $0.5 \mathrm{~g}$ mucus production (cutoff lines) in one
CDA/histamine provocation series
100 dose
The dose $<100 \mathrm{~L}$ CDA or $1 \mathrm{mg} / \mathrm{ml}$ histamine resulting in $40 \%$ reduction of
nasal patency and/or $0.5 \mathrm{~g}$ mucus production (cutoff lines) in a CDA/
histamine provocation series
Mean 400 dose
The average of three repeat doses of which at least one resulted in a $>400$
dose after three repeat histamine or CDA challenge series performed
weekly. A positive response demonstrates the degree of nasal CDA reactivity
in patients with NANIPER. It is reproducible and sensitive but less specific
Mean 100 dose
The average of three repeat doses of which at least one resulted in a 100 dose
after three repeat histamine or CDA challenge series performed weekly. A
positive response demonstrates the presence of nasal CDA reactivity in
patients with NANIPER. It is reproducible and less sensitive than mean 400
dose, but more specific

\section{Histamine}

A cclimatization and prerinsing with $\mathrm{N}$ saline were the same as with the CD A challenges. $\mathrm{H}$ istamine was used in the concentrations 0.125 , $0.25,0.5,1,2$, and $4 \mathrm{mg} / \mathrm{ml}$ (9-11). M easurements started 1 min after provocation and continued for $4 \mathrm{~min}$, allowing adequate contact between histamine and the nasal epithelium.

\section{Statistical Analysis}

Thresholds of outcome parameters were calculated as the intersection of the dose-response curve with the effect cutoff point. R eproducibil- ity and dose dependency were assessed for the outcome parameters "nasal patency" and "mucus production" separately by calculating reliability indices (RIs) (12) at several thresholds. The RI was defined as the ratio of intersubject variance to total variance. Sensitivity and specificity were determined at the "mean 100 dose" and the "mean 400 dose" (see REPRODU CIBILITY and Table 3) and compared for CDA and histamine using Fisher's exact test.

Specificity was also calculated for maximal values and regression lines of the outcome parameters. R egression line analysis was achieved by pooling three consecutive provocation series and subsequent In transformation per patient using Biomedical Package Software (B M D P-5V ; BM D P Statistical Software, Inc., Los A ngeles, CA ). They represented the function: $\ln \left(y / y_{0}\right)=-a x$. A II regression lines started at the predefined value of $100 \%$; $a$, the slope coefficient of this regression line, represented a decline or increase per doubling of the dose step. $D$ ifferences between patients with NA NIPE R and control subjects and between provocation types were analyzed using the $\mathrm{M}$ ann-W hitney $\mathrm{U}$ test. Confidence analysis was performed using SPSS PC software (SPSS Inc., Chicago, IL ).

$A$ random coefficient model with an intersubject grouping factor in B M D P 5V software was used for (1) optimal curve estimation for outcome parameters, (2) determination of a possible change in nasal responsiveness after repeat provocations, and (3) calculations of correlation coefficients between clinical features and outcome parameters. The $M$ ann-Whitney $U$ test was used to compare carryover and treatment effects. Intrapatient and control totals for the two provocation periods were used to test the carryover effect. The differences between intrapatient and control totals for two provocation periods were used to test the treatment effect. We assumed that there was no significant carryover or treatment effect if the means of these totals did not significantly differ between the two provocation series. M edians of daily record chart data were analyzed with the M ann-W hitney $U$ test in three ways: (1) symptom score on the same day, (2) on the previous day, and (3) as an average for the preceding week. Visual A nalogue Scales for (1) patency reduction, (2) mucus production, and (3) sneezing were analyzed separately and as a total using the M annWhitney $\mathrm{U}$ test.

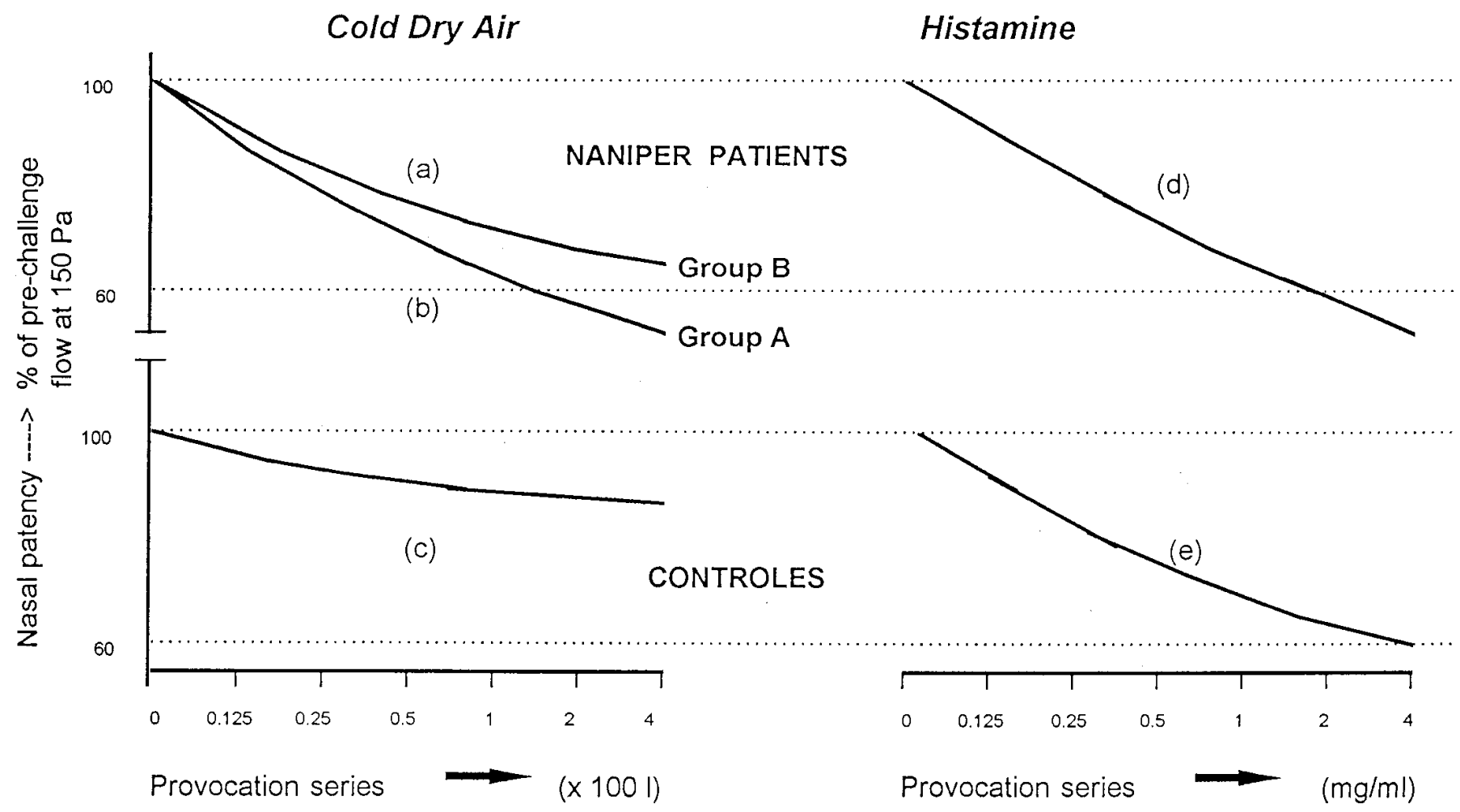

Figure 1. Optimal curve fits for observed patency results in percentages demonstrating intranasal CDA specificity and the lack of specificity after intranasal histamine challenge: Curves (a) and (b) versus (c), statistically significant different slope coefficients; curves (d) and (e) not statistically significant. External reproducibility of intranasal CDA challenge is shown: Curves (a) and (b), no statistically significant difference. 
A

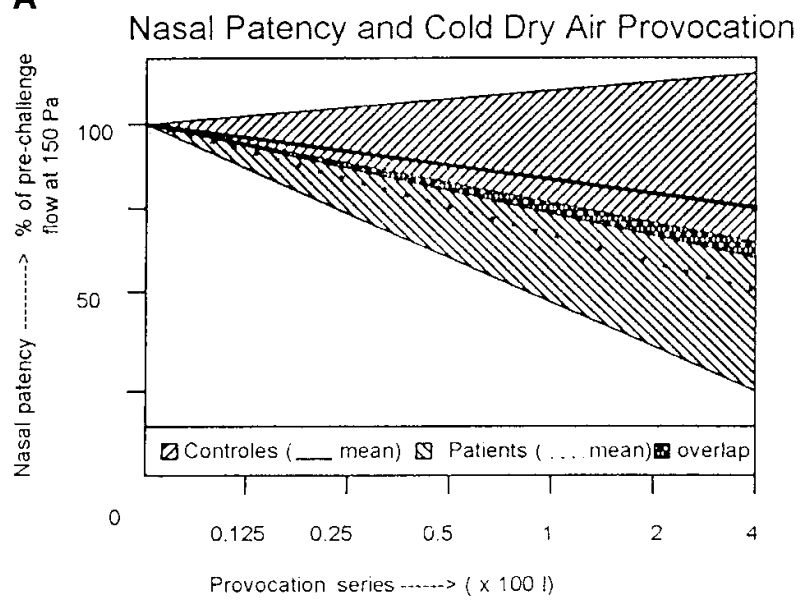

C

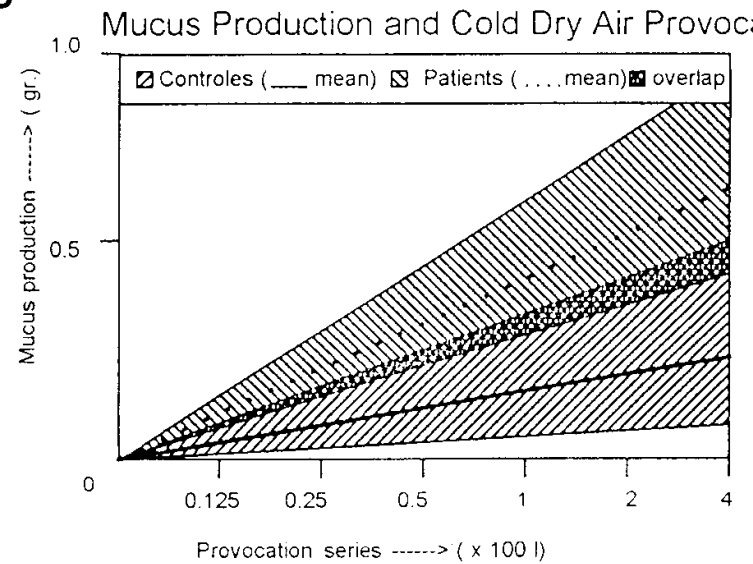

B

Nasal Patency and Histamine Provocation

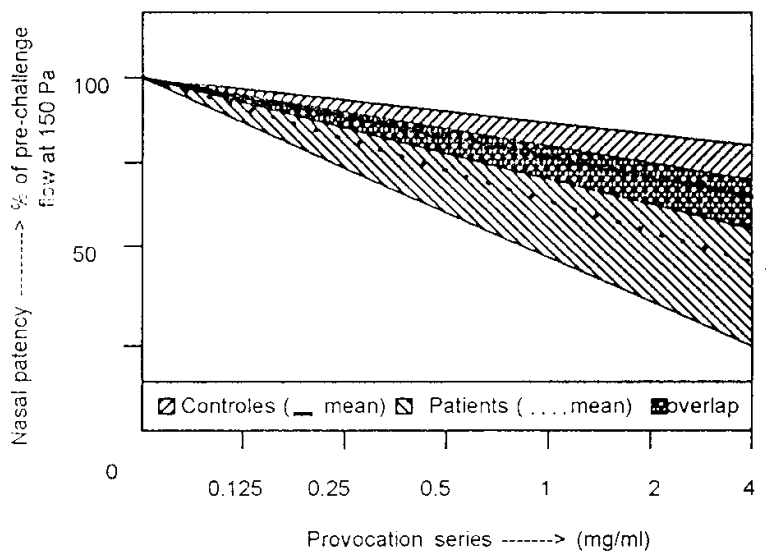

D

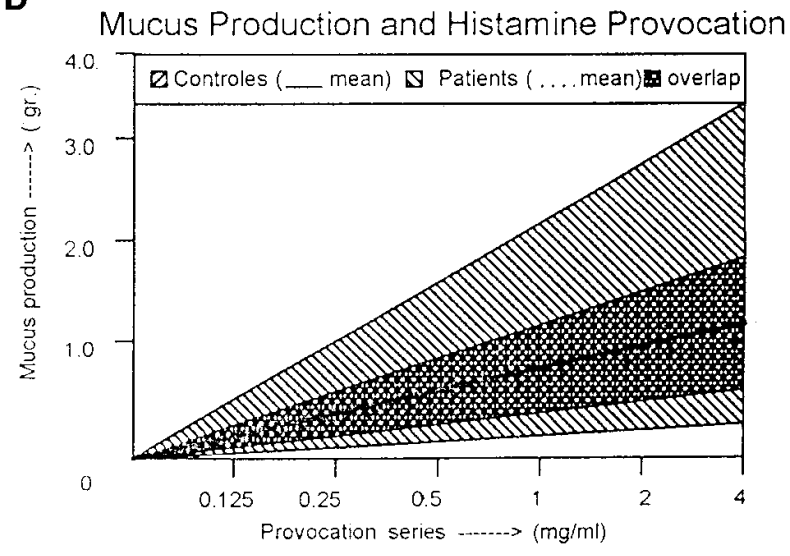

Figure 2. 95\% confidence intervals pooled over all dose steps demonstrating for mucus production and nasal patency a dose-response relationship. Less overlap between NANIPER Group A and the Control Group results for CDA- versus histamine-provoked mucus production and patency decrease is clearly visible.

\section{RESULTS}

\section{Dose Dependency}

CDA challenges were tolerated well throughout the study. CD A provocation did not lead to sneezing of any importance. $\mathrm{H}$ istamine challenge provoked sneezing, but not in a reproducible or dose-dependent manner (data not shown). Nasal patency and mucus production were dose-dependent outcome parameters. To demonstrate and illustrate specificity, maximal effects and regression lines were also assessed (see Figures 1 and 2).

\section{Threshold Doses}

Reproducibility and positivity for nasal CD A challenge. Cutoff lines of $10,20,30,40$, and $50 \%$ patency reduction or $0.2,0.3$, $0.4,0.5,0.75$, or $1.0 \mathrm{~g}$ mucus production were assessed. In order to achieve an accurate calculation of reproducibility, the first intersection of the dose-response line with the cutoff line was calculated and used to determine the reproducibility of the threshold dose. The test-retest reproducibility of one single CDA provocation was inadequate.

In order to increase reproducibility for intranasal CDA provocation, a series of three provocation series was performed. Threshold doses were calculated for three repeated provocations at intervals of $1 \mathrm{wk}$ within a 2 -wk period (mean 400 dose and mean 100 dose; see Table 3). The mean 400 dose represented the mean of three threshold doses given at intervals of $1 \mathrm{wk}$, which resulted in $40 \%$ nasal patency reduction and/or $0.5 \mathrm{~g}$ mucus production after one challenge series. This dose was used to evaluate intrapatient and interpatient differences. The mean 100 dose is similar to the mean 400 dose, with the added restriction that this dose is reached at or before 100 $\mathrm{L} C D A$ or $1 \mathrm{mg} / \mathrm{ml}$ histamine in one of the three CDA or histamine challenge series. R eproducibility was calculated by determining the reliability index (RI) (12). Mean 400 dose and mean 100 dose thresholds for CDA provocations in patients with NA NIPER resulted in a satisfactory $R$ I of $76 \%$ for nasal patency and a RI of $86 \%$ for mucus production. The RIs of histamine challenge in patients with NANIPER for these thresholds were 65 and $92 \%$, respectively. For control subjects, these R Is for patency and mucus production thresholds were, respectively, 32 and $65 \%$ after CD A and 69 and $77 \%$ after histamine challenge. Thresholds at the other cutoff points mentioned above resulted in lower $\mathrm{R}$ Is for CD A reactivity. A S a rule, histamine reactivity also resulted in lower $\mathrm{R}$ Is (results not shown). When patients reached the mean 100 dose they were considered to be CDA reactive. For statistical reasons, patients who did not reach the 400 dose were considered to have a threshold of $800 \mathrm{~L} \mathrm{CDA}$ or $8 \mathrm{mg} / \mathrm{ml}$ histamine. When reaching the 400 dose or the 100 dose after $N$ saline, $6.25 \mathrm{~L}$ CD A (or $0.0625 \mathrm{mg} / \mathrm{ml}$ histamine) was adopted as the basis for calculations. 
TABLE 4

DESCRIPTION OF NANIPER GROUPS A AND B AND CONTROL GROUP UNDER STUDY*

\begin{tabular}{|c|c|c|c|c|c|c|c|c|c|c|}
\hline \multirow[b]{2}{*}{ Subjects } & \multirow[b]{2}{*}{ Age (yr) } & \multirow{2}{*}{$\begin{array}{l}\text { Baseline } \\
\text { Patency }^{\dagger} \\
\text { CDA 1-3 }\end{array}$} & \multirow{2}{*}{$\begin{array}{c}\text { Baseline } \\
\text { Patency }^{\dagger} \\
\text { Histamine 1-3 }\end{array}$} & \multicolumn{6}{|c|}{ CDA Dose in Doubling Dose Steps ${ }^{\ddagger}$} & \multirow{2}{*}{$\begin{array}{l}\text { Total lgE } \\
(\mathrm{E} / \mathrm{ml})\end{array}$} \\
\hline & & & & CDA1 & CDA1 & CDA3 & HIST1 & HIST2 & HIST3 & \\
\hline $\begin{array}{l}\text { NANIPER Group A, } \\
n=16\end{array}$ & $44 \pm 10.9$ & $527.6 \pm 163.5$ & $518.2 \pm 185.2$ & $4.25 \pm 1.78$ & $3.93 \pm 2.46$ & $3.88 \pm 2.29$ & $1.59 \pm 1.28$ & $2.65 \pm 1.85$ & $1.90 \pm 1.71$ & $48 \pm 24.6$ \\
\hline $\begin{array}{l}\text { NANIPER Group B, } \\
n=16 \\
\text { Control group, } \\
n=7\end{array}$ & $37 \pm 12$ & $856.7 \pm 139.5$ & $792.8 \pm 176.5$ & $4.56 \pm 1.63$ & $6.57 \pm 0.78$ & $5.72 \pm 2.36$ & $2.85 \pm 1.67$ & $4.43 \pm 1.13$ & $3.0 \pm 2.0$ & $160.0 \pm 45.0$ \\
\hline
\end{tabular}

* Values are mean \pm SD. Baseline patency and threshold doses are normally distributed within population groups in this study.

† Flow in $\mathrm{ml} / \mathrm{s}$ at $150 \mathrm{~Pa}$.

₹ $1=0.12 \mathrm{mg} / \mathrm{ml}$ histamine or $12.5 \mathrm{~L} \mathrm{CDA} ; 6=4 \mathrm{mg} / \mathrm{ml}$ histamine or $400 \mathrm{~L} C D A$.

Sensitivity, specificity, and degree of nasal CDA challenge. The first dose step resulting in the 400 dose was considered to be a positive reaction to intranasal CDA (Table 4). Sensitivity was calculated as the number of patients with NA NIPER responding positively to intranasal CD A divided by the total of patients with NA NIPER $\times 100 \%$. Specificity was calculated as the number of control subjects with one or more positive reactions (false positives) $\times 100 \%$. The mean 400 dose resulted in a comparable sensitivity for CD A and histamine, 100 and $94 \%$, respectively, whereas specificity was better for CD A at $42 \%$ as opposed to $0 \%$. This difference in specificity was even more evident for the mean 100 dose (Table 5). The specificity of CDA compared with that of histamine was $71 \%$ as opposed to $0 \%$. Sensitivity for the mean 100 dose was a little less when compared with the mean 400 dose at $87 \%$ as opposed to $94 \%$ (Table 5). For other histamine thresholds (for patency and mucus production separately, or for a combination of patency and mucus production) a combination of less sensitivity and specificity was found (results not shown).

The intrapatient standard deviations (SD s) for the doubleddose provocation steps were determined in order to assess the degree of nasal reactivity to the mean 400 dose. $D$ ata for 15 of the 16 patients were available. For nasal patency, respectively, mucus production after CD A SD s were 1.1 and 0.9 . For histamine provocation these SD s were 0.8 versus 1.3 . The same SD s were found for the mean 100 dose.

In short, the presence of CDA reactivity in NA NIPER was best described by the mean 100 dose. This was a dose-dependent, reproducible, sensitive, and specific threshold dose. Specificity was in favor of CDA rather than of histamine $(p<0.05)$. Sensitivity was the same for both provocation methods $(p=$ 0.35 ). The degree of nasal CDA reactivity in NA NIPER was best described by the mean 400 dose. This dose was reproducible and sensitive but less specific than the mean 100 dose.

\section{Maximal Effects Over all Dose Steps and Regression Lines}

The CDA challenge was superior to histamine in discriminating between patients with NA NIPER and control subjects for data of maximal effects on patency (CDA : $p=0.003$; histamine: $p=0.052$ ) and for the same data of mucus production (CD A : $p=0.001$; histamine: $p=0.023$ ) (see Table 6).

A significant difference was found between the patency slope coefficients of Group A and those of Group B patients with NA NIPER compared with control subjects (NA NIPER $G$ roup $A$ versus control subjects: $p=0.04$ ). No statistical significance was found between these curve slopes for histamine $(p=0.30)$. In the case of mucus production, the differences between patients with NANIPER and control subjects were even more apparent than for nasal patency (CD A : $p=0.0021$; histamine: $p=0.16$ ) (see Table 6).

In short, CDA provocation-expressed as maximal effects and regression lines-resulted in better discrimination between patients with NANIPER and healthy control subjects than did histamine provocation in terms of both nasal patency and nasal mucus production. This is shown by the confidence intervals for nontransformed data (Figure 2).

Variability. V ariability after histamine provocation was greater in patients with NA NIPER than after CD A challenge (see Figure 3). In control subjects, however, histamine challenge resulted in lower variability than did CD A challenge.

External reproducibility. A second group of 16 patients with NA NIPER (G roup B) was subjected to one CDA provocation session in order to assess whether the patency and mucus production data for other patients with NA NIPER (those who did not meet additional restrictions) corresponded to those of Group A (external reproducibility). A fter plotting the mucus production and patency data of patients from $G$ roup $A$, a best-fit function was found to describe the patency data only: $\ln \left(y / y_{0}=-\beta x\right.$ or $y=y_{0} e^{-\beta x}$, where $y=$ nasal patency $(\mathrm{ml} / \mathrm{s}) ; y_{0}=$ preprovocation patency value; $x=$ dose step (preprovocation $\mathrm{x}=0$; $400 \mathrm{~L} \mathrm{CDA}$ or $4 \mathrm{mg} / \mathrm{ml}$ histamine $\mathrm{x}=$ 6); $\beta=$ slope coefficient.

Patency data after CDA provocation resulted in mean slope coefficients $\beta$ for NA NIPER Groups A and B of 0.110 and 0.077 , respectively. The difference between the groups (0.033) was not statistically significant ( $p=0.14$; $95 \%$ confidence interval: 0.022 to 0.045 ), thus demonstrating external reproducibility. For control subjects, $\beta=0.026$. It was not possible to find an adequate function to describe mucus production.

Correlation between clinical parameters and nasal reactivity. (1) Prerinsing the nose with N saline, (2) patient's perception

TABLE 5

\section{SENSITIVITY AND SPECIFICITY RESULTS FOR CDA AND HISTAMINE CHALLENGES CALCULATED AT MEAN 100 DOSE AND MEAN 400 DOSE*}

\begin{tabular}{|c|c|c|c|}
\hline \multicolumn{2}{|c|}{ Cold Dry Air } & \multicolumn{2}{|c|}{ Histamine } \\
\hline Sensitivity & Specificity & Sensitivity & Specificity \\
\hline Mean 100 dose & & & \\
\hline 14/16 (87\%) & $5 / 7(71 \%)$ & $16 / 16(100 \%)$ & $0 / 7(0 \%)$ \\
\hline Mean 400 dose & & & \\
\hline 15/16 (94\%) & $3 / 7(42 \%)$ & $16 / 16(100 \%)$ & $0 / 7(0 \%)$ \\
\hline
\end{tabular}

* The sensitivity of the two challenge types is more or less equal. The specificity of histamine challenge, on the other hand, is far less than that of CDA provocation. Only combined patency and/or mucus production data were assessed. For patency and mucus production data taken separately, similar percentages were found (data not shown). 
TABLE 6

RESULTS FOR THE ALTERNATIVE OUTCOME PARAMETERS: MAXIMUM EFFECT AND REGRESSION LINE ANALYSIS*

\begin{tabular}{|c|c|c|c|c|c|c|}
\hline & \multicolumn{2}{|c|}{ Maximum Effect } & \multicolumn{2}{|c|}{ Regression Line } & \multirow[b]{2}{*}{$\begin{array}{c}95 \% \\
\text { Confidence }\end{array}$} & \multirow[b]{2}{*}{$\begin{array}{c}95 \% \\
\text { Confidence }\end{array}$} \\
\hline & Patency & $\begin{array}{c}\text { Mucus } \\
\text { Production }\end{array}$ & Patency & $\begin{array}{c}\text { Mucus } \\
\text { Production }\end{array}$ & & \\
\hline \multicolumn{7}{|l|}{ CDA } \\
\hline Patient Group A & 0.51 & 0.72 & -8.13 & 0.12 & -11.0 to -5.2 & 0.066 to 0.16 \\
\hline Control group & 0.26 & 0.27 & -2.70 & 0.04 & -5.7 to 3.4 & 0.006 to 0.071 \\
\hline $\mathrm{p}$ Values & $p=0.003$ & $p=0.001$ & $p=0.04$ & $p=0.0021$ & & \\
\hline \multicolumn{7}{|l|}{ Histamine } \\
\hline Patient Group A & 0.67 & 1.53 & -9.17 & 0.18 & -12.4 to -5.9 & 0.09 to 0.60 \\
\hline Control group & 0.42 & 0.94 & -6.30 & 0.19 & -8.6 to -4.2 & 0.088 to 0.28 \\
\hline $\mathrm{p}$ Values & $p=0.052$ & $p=0.023$ & $p=0.30$ & $p=0.16$ & & \\
\hline
\end{tabular}

* The specificity of CDA provocation is shown by the significant differences between patients with NANIPER and control subjects. Histamine challenge failed to make this distinction. Note that a $0.071 \mathrm{~g}$ increase of mucus production per dose step after CDA challenge indicates NANIPER.

of the nasal symptoms as expressed by a daily record chart or visual analogue scale, and (3) the color of the nasal mucosa were not statistically significant correlated with the mean 400 dose or the mean 100 dose.

Tachyphylaxis: increased responsiveness, carryover, or treatment effect? The responses to 100 dose and 400 dose (see Table 3) of CDA /histamine provocation series on D ay 5 were compared with the responses to the mean 100 dose and mean 400 dose administered during the previous 2 wk. No statistically significant change was noted in the response to the 100 dose and the 400 dose during the CDA provocation period. $\mathrm{H}$ istamine provocation, however, gave an increased responsiveness effect for the 100 dose and the 400 dose ( $p=0.025)$. A carryover effect was not found ( $p=0.13$ ). Nor was any treatment effect of histamine after CDA or vice versa found $(p=0.27)$.

\section{DISCUSSION}

This study has shown that, unlike histamine, intranasal CDA provocation is a reliable method for measuring nasal reactivity symptoms in patients with NANIPER in a dose-dependent and, for patients with NANIPER, recognizable way. CDA challenge is a natural stimulus, although exposure conditions are artificial. CDA is thought to provoke neurogenic reflex mechanisms in the nasal mucosa $(2,3)$. In this study, the assessment of intranasal CDA reactivity is based on nasal patency and mucus production as the two main outcome parameters, making the method very suitable for studying nasal hyperreactivity in patients with NA NIPE R (blockers and runners). A Ithough time-consuming, it has been found to be a well tolerated, safe, and easy to dose provocation method. I ts relation to histamine and the separate assessment of patency

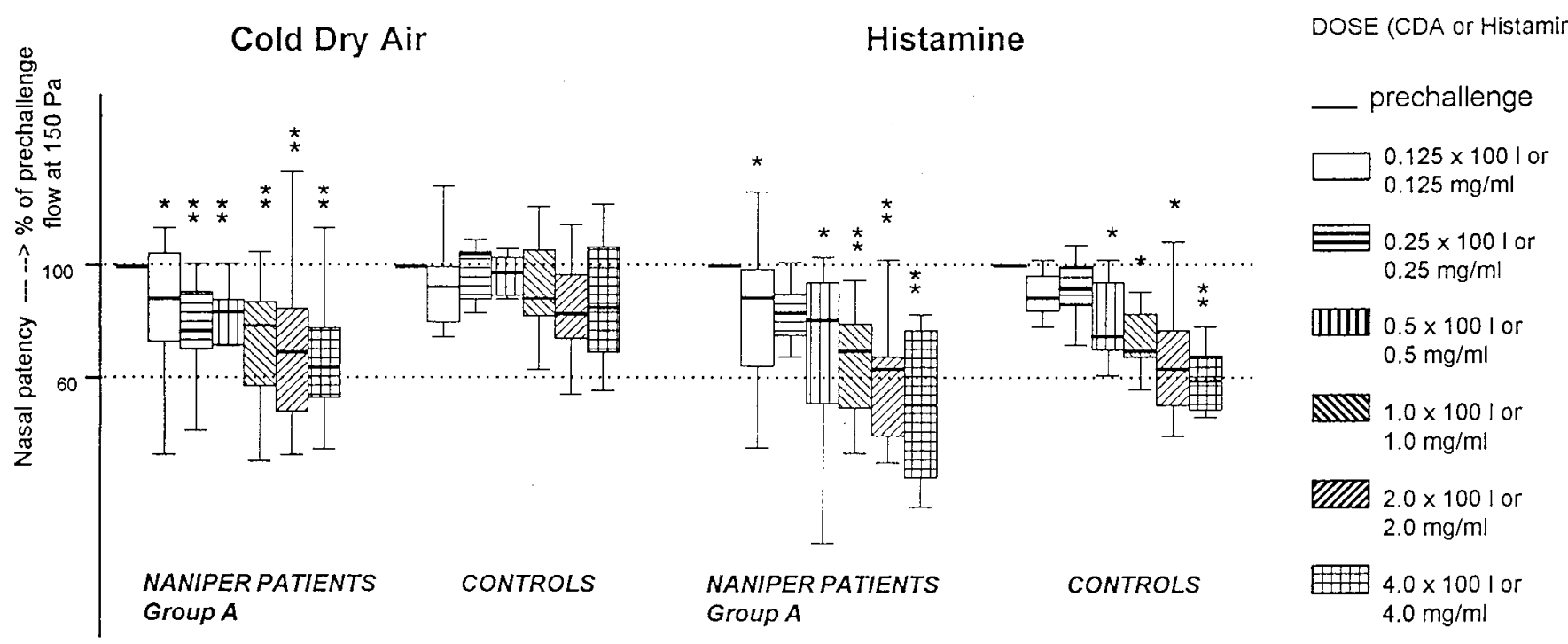

Boxplot: box $=25$ to 75 percentile; bold line - median value; whiskers show $95 \%$ reliability index

Figure 3. Box plot diagrams demonstrating a large variability of patency results of patients with NANIPER after histamine provocation compared with CDA provocation. In control subjects no significant differences were found between CDA provocation doses and prechallenge values, whereas histamine showed a significant decrease. ${ }^{*} p<0.05,{ }^{* *} p<0.01$ (paired t test). 
reduction, mucus production, and sneezing have, to our knowledge, not been studied previously.

Patients with NA NIPER are an interesting group to study because no single test had been developed until now for monitoring changes in this condition. A common and characteristic feature of patients with NANIPER is nasal hyperreactivity. U ntil now, the most common diagnostic test for measuring nasal hyperreactivity was intranasal histamine provocation. $\mathrm{H}$ istamine provocation, however, fails to differentiate between patients with NA NIPER and control subjects. CDA is able to make this distinction. We therefore find that $C D A$ is superior to histamine challenge for diagnosing NA NIPER . CD A challenge could be an alternative to histamine in characterizing nonspecific nasal hyperreactivity in other subgroups of rhinitis, examples being allergic $(9)$, nonallergic $(10,15)$, and infectious (14) rhinitis.

A s cigarette smoke (16) and ozone (17) have been proven to induce airway hyperreactivity, we tried to eliminate these factors in the first group of patients with NA NIPER (G roup A ), as mentioned in Table 1. We were able to demonstrate corresponding results for nasal patency in a second $\mathrm{NA}$ NIPE R group without these additional restrictions ( $G$ roup $B$ ), indicating that in this study these environmental factors were not of major importance.

A reproducible measure for intranasal CDA provocation was difficult to establish. Sneezing, one of the three outcome parameters, was not useful. Several criteria for mucus production and patency such as maximal effects, regression line coefficients, and threshold doses at several cutoff points were assessed. Single measurements did not result in a reproducible measure. In order to achieve acceptable reproducibility and sensitivity in both histamine and CD A challenges, requiring as little time as possible, repeated measurements expressed as mean 100 dose and mean 400 dose (see Table 3) were needed. $\mathrm{H}$ owever, specificity was acceptable only in the case of CD A challenge. It was not possible to achieve comparable specificity for histamine challenge using other threshold doses.

In this study, three complete provocation series were performed. This study has demonstrated that the 100 dose is indicative of the presence of CD A reactivity. A s soon as the 100 dose is reached, the subsequent dose steps in the series are unnecessary. The degree of CDA reactivity will be indicated by the mean 400 dose. It will be possible to note changes in CDA reactivity, bearing in mind intrasubject variability.

R epeated daily CD A or histamine provocations for $5 \mathrm{~d}$ did not lead to increased responsiveness for CD A, but it did so for histamine. Some studies $(18,19)$ report unchanged nasal responsiveness to histamine after repeated histamine challenges, but these studies are difficult to compare to ours. G ronburg and colleagues (18) rechallenged nonrhinitic subjects after $1 \mathrm{~h}$ and $1 \mathrm{~d}$, whereas $\mathrm{O} \mathrm{hm}$ and J uto (19) rechallenged nonallergic rhinitis subjects on three to seven occasions, sometimes at intervals of several weeks. A possible explanation for our finding that repeated histamine challenges lead to increased responsiveness could be that we used five consecutive daily provocations and that these resulted in increased inflammation. Söderberg and colleagues (20) found that bronchial histamine challenges lead to an increase in inflammatory cells in bronchoalveolar fluid $24 \mathrm{~h}$ after the inhalation of histamine in normal subjects.

Surprisingly, several clinical parameters such as symptom scores and visual analogue scales correlated poorly with CD A and histamine reactivity in patients with NA NIPER. In patients with perennial allergic rhinitis, however, De G raaf and colleagues (21) found significant correlations between nasal responsiveness to histamine and symptom scores for the pre- ceding $2 \mathrm{wk}$. H allen and J uto (22) found reasonable correlations between symptom scores for the preceding $2 \mathrm{wk}$ and histamine reactivity of nasal mucosa in nonallergic nasal-hyperreactive patients. The reason for the conflict with our findings could be that the thrice-weekly CD A /histamine provocations interfered with the natural symptomatology of NA NIPER.

Earlier biopsy studies in patients with NA NIPER did not support the hypothesis of cellular inflammation (4). This emphasizes the need for further investigation of neurogenic structures and mediators such as neuropeptides in hyperreactive nasal mucosa. Further studies evaluating the effects of $\mathrm{CDA} /$ histamine challenge on these parameters are in progress.

This new standardized intranasal CDA provocation method uses a recognizable natural nonspecific stimulus and seems to be more suitable than histamine for characterizing and assessing the presence and degree of nasal reactivity in NA NIPER .

Acknowledgment: The writers wish to thank Prof. C. D. A. Verwoerd for valuable comments, and Miss E. van Schaik for assisting with patient matters.

\section{References}

1. Wihl, J. A., G. K unkel, and E. Middleton. 1985. Perennial rhinitis. In N. M ygind and B. Weege, editors. A llergic and $V$ asomotor R hinitis: Clinical A spects. M unksgaard, Copenhagen. 36.

2. Kubo, N., and T. K umazawa. 1993. Functional disturbances of the autonomic nerve in nasal hyperreactivity: an up-date review. A cta O tolaryngol. Suppl. (Stockh.) 500:97-108.

3. Ä nggard, A. 1993. B asic mechanisms in autonomic nervous response in specific and nonspecific nasal hyperreactivity. A cta O tolaryngol. (Stockh.) 113:394-396.

4. Blom, H. M., T. G odthelp, W. J. Fokkens, A. K leinj an, A. F. H olm, T. M . V room, and E. R ijntjes. 1995. M ast cells, eosinophils and IgE -positive cells in the nasal mucosa of patients with vasomotor rhinitis: an immunohistochemical study. A rch. O torhinolaryngol. 252:S33-S39.

5. van L ier, L. A . J . 1960. E en vergelijkende studie over de rhinitis vasomotorica allergica en non-allergica. Thesis RU Leiden, Zuid-Nederlandse D rukkerij, The N etherlands.

6. Philip, G., R. Jankowski, F. M. B aroody, R. M. Naclerio, and A. G . Togias. 1993. R eflex activation of nasal secretion by unilateral inhalation of cold dry air. A m. Rev. Respir. D is. 148:1616-1622.

7. Togias, A. G., R. M. Naclerio, D. Proud, J. E. Fish, F. A dkinson, A. Kagey-Sobotka, P. S. Norman, and L. M. Lichtenstein. 1985. N asal challenge with cold, dry air results in release of inflammatory mediators: possible mast cell involvement. J. Clin. Invest. 76:1375-1381.

8. W esseling, G. J ., I. M . V anderhoven-A ugustin, and E. F. W oulters. 1993. Forced oscillation technique and spirometry in cold air provocation tests. Thorax 48:254-259.

9. G erth van W ijk, R ., and P. H. D ieges. 1994. N asal reactivity to histamine and metacholine: two different forms of upper airway responsiveness. Rhinology 21:119-122.

10. Gerth van Wijk, R., and P. H. Dieges. 1991. Nasal hyperresponsiveness to histamine, metacholine and phentolamine in patients with perennial non-allergic rhinitis and in patients with infectious rhinitis. Clin. O tolaryngol. 16:133-137.

11. Hargreave, F. E., G. R yan, N. C. Thomson, P. M. O'B yrne, K. Latimer, E. F. J uniper, and J. Dolovich. 1981. B ronchial responsiveness to histamine or methacholine in asthma: measurements and clinical significance. J. Allergy Clin. I mmunol. 68:347-355.

12. Fleiss, J. L. 1986. R eliability of measurement. In The D esign and A nalysis of Clinical Experiment. J. W iley and Sons, N ew Y ork.

13. A Ibegger, K. 1988. A ktuelle aspekte der nasalen hyperreagibilität. H NO 36:389-398.

14. J acoby, D. B., J . Tamoki, D . B. Borson, and J . A . N adel. 1989. Influenza infection causes airway hyperresponsiveness by decreasing enkephalinase. J. A ppl. Physiol. 98:1077-1079.

15. Mack ay, J. S. 1994. Intranasal steroids and non-allergic rhinitis. Eur. Respir. J. 20:245-247.

16. Dusser, D. J ., T. D. D jokic, D. B. Borson, and J . A . N adel. 1989. Cigarette smoke induces bronchoconstrictor hyperresponsiveness to substance $P$ and inactivates airway neutral endopeptidase in the guinea pig: possible role of free radicals. J . Clin. Invest. 84:900-906.

17. Gordon, T., C. S. V enugopalan, M. O. A mdur, and J. M. D razen. 1984. 
O zone induced airway hyperreactivity in the guinea pig. J. A ppl. Physiol. 57:1034-1038.

18. Gronburg, H., P. B orum, and N. M ygind. 1986. Histamine and methacholine do not increase nasal reactivity. Clin. A llergy 16:597-602.

19. O hm, M ., and J. E. J uto. 1993. $\mathrm{N}$ asal hyperreactivity: a histamine provocation model. R hinology 31:53-55.

20. Söderberg, M., R. L undgren, L. B jermer, N. Stjernberg, and L. R osenhall. 1988. Inflammatory response in bronchoalveolar lavage fluid after inhaling histamine. A llergy 43:98-102.
21. De Graaf-in 't V eld, C., S. K oenders, I. M. G arrelds, and R. G erth van Wijk. 1996. The relationships between nasal hyperreactivity, quality of life and nasal symptoms in perennial allergic rhinitis. In $\mathrm{Nasal} \mathrm{H} \mathrm{y-}$ perreactivity and Inflammation in Perennial A llergic R hinitis. D octoral Thesis E rasmus U niversity, R otterdam, The N etherlands. 1996.

22. H allen, H ., and J J uto. 1991. Correlation between subjective and objective assessment of nasal hyperreactivity. ORL J. Otorhinolaryngol. Relat. Spec. 56:51-61. 